\section{Aportes de la investigación-acción participativa a una teología de los signos de los tiempos en América Latina*}

\section{Carolina Bacher-Martínez ${ }^{* *}$}

RECIBIDO: 22-06-16. APROBADO: 04-11-16

Resumen: El trabajo postula la convergencia entre una teología de los signos de los tiempos en América Latina y el método de la investigación-acción participativa, cuyo referente principal en sociología es el colombiano Orlando Fals Borda. Para ello correlaciona los fundamentos y los procedimientos que constituyen sendos marcos teóricos y elabora una propuesta teológico-pastoral de recepción preliminar, ofreciendo una ponderación de las posibilidades y dificultades que conlleva la práctica teológica de este enfoque.

PALABRAS ClaVE: Investigación-acción participativa, signos de los tiempos, método teológico, América Latina, teología latinoamericana, teología pastoral.
Contributions of the Participatory Action Research (PAR) to a Theology of the Signs of the Times in Latin America

Авstract: This article postulates the convergence between a Theology of the signs of the times in Latin America and the Participatory Action Research method, whose main reference in Sociology is the Colombian Orlando Fals Borda. The text correlates the foundations and procedures that constitute the theoretical frameworks of both, Theology of the signs of the times in Latin America and Participatory Action Research, and also develops a theologicalpastoral proposal of preliminary reception by offering a weighting of the possibilities and difficulties that the theological practice of this approach entails.

Key Words: Participatory Action Research, Signs of the Times, Theological Method, Latin America, Latin American Theology, Pastoral Theology.

\section{PARA CITAR ESTE ARTÍCULO:}

Bacher Martínez, Carolina. "Aportes de la investigación-acción participativa a una teología de los signos de los tiempos en América Latina”. Theologica Xaveriana 184 (2017): 309-332. https://doi.org/10.11144/ javeriana.tx67-184.aiptst

\footnotetext{
* Estudio presentado en las Jornadas del Centro Teológico Manuel Larraín (8 y 10 de agosto de 2014), en Las Brisas, Chile. Se enmarca en la investigación doctoral titulada "Tesoros escondidos. Aportes de la investigación-acción participativa (IAP) al método de la teología pastoral. Estudio teológico pastoral a partir de siete casos de interacción entre teología y comunidades cristianas en América Latina”.

** Licenciada y Bachiller en Teología, Facultad de Teología, Universidad Católica Argentina, Buenos Aires. Profesora asistente en la misma Facultad y profesora titular, Instituto Superior del Profesorado Don Bosco, Buenos Aires; participante en el programa de investigación "Teología de los signos de los tiempos” coordinado por la doctora Virginia R. Azcuy, del Centro Teológico Manuel Larraín, Santiago de Chile. OrCid: 0000-0003-2541-6830. Correo electrónico: carobacher19@gmail.com
} 


\section{Introducción}

Este artículo postula la convergencia entre el método de la investigación-acción participativa (IAP) -original de las ciencias sociales y actualmente extendido en diversas disciplinas- y la teología de los signos de los tiempos que se ha desarrollado en América Latina ${ }^{1}$, tanto en su dimensión teórica como práctica. El discernimiento de la convergencia pasa por encontrar aspectos semejantes: una "red de parecidos que se superponen y entrecruzan”2 según la expresión de L. Wittgenstein.

En un primer momento, se definen y describen los componentes de la investigación-acción participativa, dando prioridad a la comprensión que de ella ha propuesto Orlando Fals Borda ${ }^{3}$. En un segundo momento se presentan sucintamente las notas de una teología de los signos de los tiempos en América Latina y algunas convergencias teóricas percibidas entre esta y la investigación-acción participativa ${ }^{4}$. En un tercer momento se proponen aportes prácticos que dicho método ofrece a la teología de los signos de los tiempos en América Latina. Por último, en un momento conclusivo se ofrecerá una ponderación preliminar de la propuesta.

\section{La investigación-acción participativa}

\section{Origen y definiciones}

El método de investigación-acción participativa surgió en torno del trabajo del colombiano Orlando Fals Borda y se presentó como tal en el Simposio Mundial

\footnotetext{
${ }^{1}$ Se considera que las investigaciones y publicaciones del Centro Teológico Manuel Larraín dan cuenta de la presencia de dicha perspectiva en diversas tradiciones teológicas posteriores al Concilio Vaticano II: Berríos, Costadoat y García (eds.), Signos de estos tiempos. Interpretación teológica de nuestra época; Azcuy, Schickendantz y Silva (eds.), Teología de los signos de los tiempos latinoamericanos. Horizontes, criterios y métodos.

${ }^{2}$ Wittgenstein, Investigaciones filosóficas § 67.

${ }^{3}$ Orlando Fals Borda (1925-2008) nació en Colombia. Cristiano de tradición presbiteriana. Estudió Música y Literatura en EE.UU.; luego realizó su Maestría y Doctorado en Sociología (Universidad Minnesota y Universidad de Florida respectivamente). A su regreso a Colombia combinó el trabajo público con la colaboración en el inicio de la Facultad de Sociología de la Universidad Nacional de Colombia, junto a Camilo Torres. Casado con la también socióloga María Cristina Salazar. Después de sus primeras producciones se alejó de la academia casi por dos décadas, para regresar en 1987. Creó la Fundación La Rosca y la revista Alternativa. Cofundador, en 1967, de Clacso. Ver a Sánchez Lópera, "Orlando Fals Borda. Aporías de un pensamiento sin desilusión”, 207-211.

${ }^{4}$ El estudio no tiene como objeto realizar una fundamentación teológica del concepto signos de los tiempos, ni de la teología que lo recepciona, para lo cual se remite a los trabajos citados en Nota 3. En dicho marco de reflexión, este trabajo busca aportar una correlación crítica entre la investigación-acción participativa y una teología de los signos de los tiempos en América Latina desde un enfoque práctico-hermenéutico para orientar la práctica de una investigación teológica que recepcione la investigación-acción participativa.
} 
realizado en Cartagena (Colombia) en 19775. A partir de entonces la investigaciónacción participativa se fue extendiendo y diversificando, tanto geográfica como disciplinariamente, al tiempo que fue asumida por diversos autores ${ }^{6}$. En 1997 se realizó el Congreso de Convergencia Participativa, también en Colombia, y en septiembre de 2000, el Noveno Congreso Mundial de la Investigación-acción Participativa, en Ballarat, Australia. Fals Borda afirmaba sobre este último encuentro:

Los presentes confirmamos con cierta satisfacción que la investigación-acción participativa ha dejado atrás los problemas de su infancia intelectual y política, y que se ha institucionalizado, como se vio, por ejemplo, en la increíble montaña de libros y revistas -la mayoría en inglés- sobre participación e investigación cualitativa que se nos ofrecieron por editores australianos y europeos en el hall del Congreso, incluso el nuevo Manual de investigación-acción, grueso volumen de 43 capítulos editado por Peter Reason y Hilary Bradbury (el Capítulo 2, de mi autoría...). También se lanzó la nueva edición del magnífico Manual de investigación cualitativa, de Norman K. Denzin e Yvonna S. Lincoln (Estados Unidos). ${ }^{7}$

Luego de un dilatado camino es posible afirmar que la investigación-acción participativa mantiene un notable dinamismo sin que falten debates en razón de las diversas líneas de fundamentación y problemas que surgen en su aplicación ${ }^{8 .}$

¿En qué consiste la investigación-acción participativa? Fals Borda la define en los siguientes términos:

Puede definirse como un método de estudio y acción que va al paso con una filosofía altruista de la vida para obtener resultados útiles y confiables en el mejoramiento de situaciones colectivas, sobre todo para las clases populares. Reclama que el investigador o la investigadora base sus observaciones en la convivencia con las comunidades, de las que también obtiene conocimientos válidos. Es inter o multidisciplinaria y aplicable en continuos que van de lo

\footnotetext{
${ }^{5}$ Para un acercamiento narrativo de los comienzos de la práctica investigación-acción participativa realizada por Fals Borda en la localidad de Montería (Córdoba, Colombia), puede consultarse a Negrete, "A la memoria del maestro Orlando Fals Borda: bases y desarrollo de la investigación-acción participativa en Córdoba (Colombia)", 85-87.

${ }^{6}$ Rahman y Fals Borda, "La situación actual y las perspectivas de la investigación-acción participativa en el mundo", 185.

${ }^{7}$ Fals Borda, "Transformaciones del conocimiento social aplicado", 284.

${ }^{8}$ Demo, Investigación participante. Mito y realidad, 105.

${ }^{9}$ Acerca de la nomenclatura afirma O. Fals Borda: "Al cabo de unos ańos, y a partir del Congreso de Cartagena, puede ya resultar conveniente deslindar claramente la IAP de la tradición clásica, positivista y psicologista de la que surgimos hace veinte o más años, como lo han exigido algunos críticos. Podemos descartar entonces la $A$ y llamarnos IP, o, para facilitar la transición, como en este libro aparece: I(A)P” (Fals Borda, Una sociología sentipensante para América Latina, 321).
} 
micro a lo macro de universos estudiados (de grupos a comunidades y sociedades grandes), pero siempre sin perder el compromiso existencial con la filosofía de vida del cambio que la caracteriza. ${ }^{10}$

Quizás sea conveniente presentar también la definición operativa de Ezequiel Ander Egg, un referente en el enfoque residente por muchos años en Argentina:

En tanto investigación, se trata de un procedimiento reflexivo, sistemático, controlado y crítico que tiene por finalidad estudiar algún aspecto de la realidad, con una expresa finalidad práctica; en cuanto acción, significa o indica que la forma de realizar el estudio es ya un modo de intervención y que el propósito de la investigación está orientado a la acción, siendo ella a su vez fuente de conocimiento; y, por ser participación, es una actividad en cuyo proceso están involucrados tanto los investigadores (equipo técnico o agentes externos), como las mismas gentes destinatarias del programa, que ya no son consideradas como simple objeto de investigación, sino como sujetos activos que contribuyen a conocer y transformar la realidad en la que están implicados. ${ }^{11}$

En el transcurso de este trabajo se desarrollan los componentes de ambas definiciones, así como los fundamentos interdisciplinarios del enfoque.

\section{Breve esbozo de sus fundamentos}

En los comienzos de su práctica de investigación, Fals Borda percibía un desafío que le permitió ir dando pasos hacia el desarrollo de la investigación-acción participativa. Recordaba, en 1979, un interrogante vital de sus inicios: “¿Qué exigencias nos ha hecho y nos hace la realidad del cambio en cuanto a nuestro papel como científicos y en cuanto a nuestra concepción y utilización de la ciencia?" ${ }^{12}$ La reconfiguración de su práctica investigativa y la formulación teórica sobre la misma permitieron desarrollar la investigación-acción participativa.

Víctor M. Moncayo, al presentar una recopilación de escritos de Fals Borda, ofrece una síntesis de las influencias teóricas de la cosmovisión del autor, e indica los aspectos que han sido relevantes: (1) La misma práctica de la investigación en campo sobre la violencia en Colombia; (2) la revisión de la sociología comprometida en diálogo con otros científicos sociales de su país y de otros países como Argentina, Venezuela, Chile, Brasil; y (3) los aportes de Sartre, Marcuse, Gorz, Marx, que lo conducen hacia una ciencia social crítica ${ }^{13}$.

\footnotetext{
${ }^{10}$ Ibíd., 320.

${ }^{11}$ Ander-Egg, Repensando la investigación-acción-participativa, 32 y 33.

${ }^{12}$ Fals Borda, Una sociología sentipensante para América Latina, 253.

${ }^{13}$ Moncayo, "Fals Borda: hombre hicotea y sentipensante", 15-16.
} 
Sin ánimo exhaustivo, sino solo ilustrativo de los autores y perspectivas que más han influido en esta metodología, lo anterior se amplía con lo expresado por el mismo Fals Borda en dos textos ponderativos de la investigación-acción participativa ${ }^{14}$. - La primera sintesis presenta el punto de partida de la trayectoria haciendo referencia a la tradición sociológica clásica de Estados Unidos y Europa en la que él se había formado ${ }^{15} \mathrm{y}$ el contacto con la investigación-acción de Sol Tax y Kurt Lewin ${ }^{16}$. Gradualmente se fue distanciando de la corriente positivista apoyada en Durkhein, Pearson y Popper, aunque resignificó las técnicas empíricas (observación, encuestas, entrevistas, etc.) con un modelo de sociología comprometida, como el de Guerreira Ramos y Costa Pinto. De Hegel asumió el método dialéctico aplicado en pasos alternos, complementarios y continuos; y de K. Marx y F. Engels, el materialismo histórico como filosofía de la historia. De A. Gramsci tomó el concepto de que el lenguaje, el folclor y el sentido común tenían una filosofía espontánea, y la necesidad de acortar la distancia entre los intelectuales y los sencillos ${ }^{17}$.

- En la segunda sintesis, hacia fines de los años 90, Fals Borda reconoce la influencia de la fenomenología de E. Husserl por medio del concepto de "vivencia"; y que, partir de H. G. Gadamer había integrado el concepto de la vivencia participante horizontal y la relación sujeto-sujeto para investigar y actuar ${ }^{18}$.

Según el mismo Fals Borda, muchos son los autores que han influido en él y en otros representantes de esta convergencia intelectual: "G. Bateson, H. G. Gadamer, J. Elliott, C. Geertz, F. Capra, A. Giddens, P. B. Checkland, I. Pregogine, T. Todorov, M. Foucault, P. Feyerabend, H. Maturana, E. Hobsbawm, N. Bobbio...Werner Heisenberg" 19 .

En sintesis, la metodología investigación-acción participativa surgió a partir de la práctica de la cosmovisión clásica de investigación-acción, revisada por la sociología

\footnotetext{
${ }^{14}$ El primero, en una publicación realizada luego del Simposio Mundial en Cartagena, "Crítica y política en ciencias sociales” (1977). El segundo, al concluir el Congreso de Convergencia Participativa, en 1997. ${ }^{15}$ Fals Borda, Una sociología sentipensante para América Latina.

${ }^{16}$ Kurt Kewin, psicólogo alemán nacionalizado estadounidense (1890-1947). "El programa lewiniano estaba centrado en la idea de adquirir conocimientos en y por la acción, al mismo tiempo que los participantes del programa estaban asociados en el estudio e implicados en la solución del problema planteado. Esto es lo que Lewin llamó action-research, una forma de adquirir conocimientos sobre un problema social y, al mismo tiempo, inducir cambios orientados a resolver el problema que era objeto de estudio" (Ander Egg, Repensando la investigación-acción-participativa, 12).

${ }^{17}$ Fals Borda, Una sociología sentipensante para América Latina, 281.

${ }^{18}$ Ibíd., 304-305, 311 y 317.

${ }^{19}$ Ibíd., 311.
} 
comprometida, y fue integrando elementos de teoría crítica, en la fundamentación y transformación de las prácticas, para finalmente sumar aportes hermenéuticos y sistémicos.

\section{Descripción del enfoque}

Fals Borda, dedicado a la investigación de la violencia en Colombia en los años 60, se preguntó por su lugar como investigador y por el lugar del conocimiento académico. Junto con otros intelectuales de la época, en América Latina, asumió una crítica abierta a la dominación imperial, y polemizó con el desarrollismo ${ }^{20}$ y con el lugar que ocupaba la academia en este proceso. En 1990, al ponderar el camino transitado, reconoció que también durante el siglo XX otros científicos y filósofos europeos reconocieron el problema y cuestionaron el propósito de sus conocimientos ${ }^{21}$. Así fue emergiendo una hermandad entre intelectuales y universitarios críticos del Norte y del Sur en orden a un mundo mejor ${ }^{22}$.

Fals Borda afirmó que "el principio de la autonomía [...] implica el reconocimiento de los talentos y fuerzas en el conjunto del pueblo que por regla general han sido bien ignorados por la clase dominante" ${ }^{23}$. Por ello, la opción por dar cabida a la participación de las clases populares reconfigura tanto las ciencias sociales ${ }^{24} \mathrm{como}$ a los sujetos que la desarrollan. Un concepto clave para la investigación-acción participativa es la comprensión del sujeto investigador como un sujeto colectivo que actúa, conoce y reflexiona. La escuela escandinava ${ }^{25}$ introdujo una comprensión holística:

La relación entre un sujeto epistémico A y un objeto empírico B en una situación de investigación social X se caracteriza, como ya lo vimos, en que el objeto es también sujeto. La estructura ABX se convierte en un sistema constituyente observable, como lo sostienen también los sistémicos del Congreso. En la mente de los participantes del sistema, la estructura se convierte en "pox" (la persona, el otro y X)... El sistema ABX/pox implica la hermenéutica doble propuesta

\footnotetext{
${ }^{20}$ Dice Sánchez Lópera: "El propio camino de Fals estuvo marcado por articulaciones impensables socialmente: ciencia y fe, positivismo y revolución, mística y empirismo; así como una conexión con una izquierda radical no necesariamente comunista que lo enfrentó a dos de los grandes universalismos del siglo XX: el capitalismo y el comunismo (de partido)" (Sánchez Lopera, "Orlando Fals Borda: la conmoción del rostro de las ciencias sociales", 199).

${ }^{21}$ Fals Borda, "El tercer mundo y la reorientación de las ciencias contemporáneas", 85.

${ }^{22}$ Ibíd., 87.

${ }^{23}$ Fals Borda y otros, Acción comunal en una vereda colombiana: su aplicación, sus resultados y su interpretación", 203.

${ }^{24}$ Villasante, "Aportaciones básicas de la IAP a la epistemología y metodología”, 25.

${ }^{25}$ Toulmin y Gustavsen (eds.), Beyond Theory: Changing Organizations Through Participation.
} 
por Giddens: una para el lenguaje cotidiano u ordinario y otra para el técnico, que deben interpenetrarse por medio del diálogo con el fin de alcanzar la comprensión y crear nuevos lenguajes; de allí depende también la calidad de la comunicación entre A y B. El mecanismo o cemento que vincula este sistema en la práctica es el lenguaje cotidiano. ${ }^{26}$

La comprensión del lugar del investigador en el proceso de conocimiento comunitario es autoimplicativa: "la investigación participativa [...] reclama que el investigador o investigadora base sus observaciones en la convivencia con las comunidades, de las que también obtiene conocimientos válidos" ${ }^{27}$. Los intelectuales y las comunidades "sienten que están aprendiendo juntos [...] vibran en una tarea conjunta y creativa para ambos, aunque lo vivan de distinta forma" 28 . A su vez, el investigador es parte de la realidad investigada y debe también analizarse y ser analizado ${ }^{29}$.

Como consecuencia directa para la producción del conocimiento se concreta y sostiene una articulación entre el saber popular y el saber académico que valora la sabiduría popular, el sentido común y la cultura del pueblo, para crear conocimientos científicos ${ }^{30} y$ generar la posibilidad de aportes mutuamente fructuosos. Se toma como punto de partida de la investigación la necesidad sentida por la comunidad y mediante las preguntas problematizadoras se establece un proceso que permite percibirla como una necesidad real. ${ }^{31}$ La propuesta se aleja tanto de canonizar el conocimiento científico como el popular:

Los pueblos comunes no siempre tienen la razón, como tampoco los llamados "doctores". Al recibir y considerar sin prejuicios la sabiduría popular y el sentido común, el conocimiento académico interdisciplinario puede propiciar críticamente una comprensión holística o más completa de la realidad, y así enriquecer y simplificar formas y estilos de la comunicación con las comunidades estudiadas..$^{32}$

La reflexión desde y sobre la praxis y para su transformación requirió -en las experiencias realizadas- de un diálogo interdisciplinario con la historia, la política, la economía, la educación y el trabajo social. Se fueron precisando los procedimientos para articular las escalas "lo micro a lo macro de universos estudiados (de grupos a

\footnotetext{
${ }^{26}$ Fals Borda, Una sociología sentipensante para América Latina, 313.

${ }^{27}$ Ibíd., 320.

${ }^{28}$ Villasante, “Aportaciones básicas de la IAP a la epistemología y metodología”, 27.

${ }^{29}$ Ibíd., 309.

${ }^{30}$ Fals Borda, Una sociología sentipensante para América Latina, 279.

${ }^{31}$ Villasante, "Aportaciones básicas de la IAP a la epistemología y metodología”, 31.

${ }^{32}$ Ibíd., 329.
} 
comunidades y sociedades grandes)" ${ }^{33}$, para favorecer que el conocimiento significativo se difunda tanto entre los académicos como entre los pueblos involucrados en los procesos históricos. Esto implicó partir de la realidad, considerando su dimensión compleja, ambivalente e interiormente contradictoria, y tratar de encontrar las potencialidades de lo que está oculto o aplastado por las estructuras culturales y políticas ${ }^{34}$.

La lectura de Habermas influyó en la comprensión de la comunidad investigadora como comunidad de comunicación y sirvió para fundamentar que el diálogo es una mediación metodológica para la comprensión de la realidad: “...hacer investigación participativa es aceptar que toda investigación sea interacción comunicante, en la que ocurre un proceso de diálogo de aprendizaje mutuo y de mutua confianza entre el investigador y el investigado" ${ }^{35}$. Por tanto, es necesario generar las condiciones de posibilidad de este proceso comunicativo ${ }^{36}$. A modo ilustrativo, T. Villasante propone considerar los discursos diversos que se hacen presentes en la interacción: silencios de las bases, estereotipos de los comunicadores, ideologías de los grupos e imágenes del $\operatorname{poder}^{37}$.

La investigación-acción participativa subraya que la finalidad del conocimiento no es solo -ni prioritariamente- académica sino que posee una finalidad práctica: “...la investigación-acción participativa quiere ser a la vez puente hacia formas más satisfactorias de explicación de las realidades y herramienta de acción para trasformar esas realidades" ${ }^{38}$. Es una metodología de estudio y acción que busca obtener resultados útiles y confiables para mejorar las situaciones colectivas, especialmente de los grupos populares ${ }^{39}$. Solo así la sociología puede proponer nuevas y más responsables técnicas proyectivas ${ }^{40}$.

La investigación-acción participativa resignifica las técnicas utilizadas tanto en el trabajo cuantitativo como cualitativo en las ciencias sociales (cuestionarios, entrevistas, observación participante, grupos focales, fuentes documentales, etc.), al inscribirlas en un proceso espiralado, dialógico y participativo, que implica el diseño

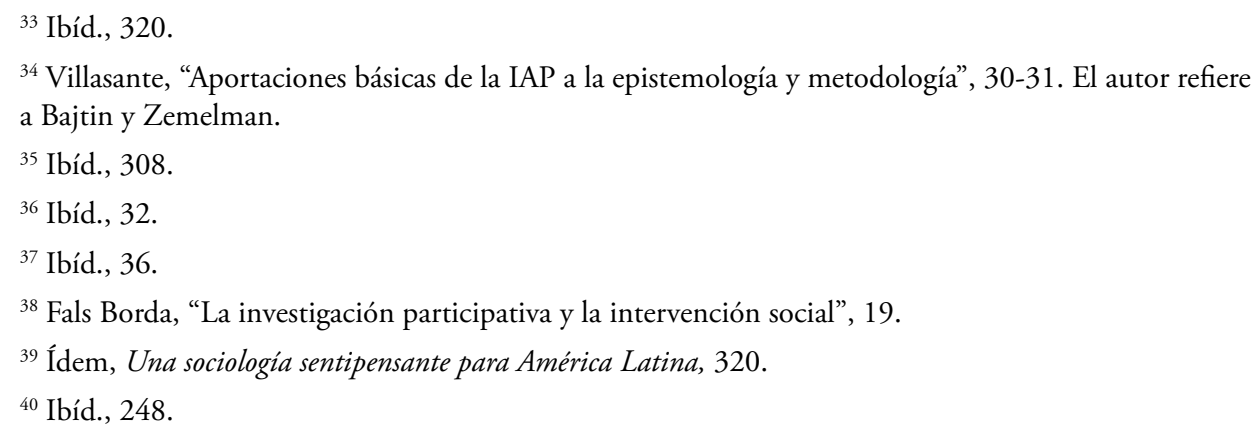


de un procedimiento para que el colectivo investigador: (1) Avance progresivamente a la conciencia y enunciación del objeto de la investigación y la acción; (2) pase por diversas instancias de recopilación de información relevante, enunciación, análisis, conceptualización y síntesis; (3) propuesta y concreción de una acción transformativa, (4) que a su vez pueda ser el punto de partida de una nueva reflexión ${ }^{41}$. El rol del investigador no solo consiste en intervenir con teorías sino también en "reintroducir expresiones desapercibidas de algún sector de la base" ${ }^{\text {"2. }}$.

Fals Borda afirmó que "existen casos de convergencia intelectual" 43 entre la investigación-acción participativa y algunos enfoques de otras disciplinas. Según el autor, serían los siguientes: (1) En educación, la escuela de educación crítica, que desarrolló las teorías de Iván Illich y Paulo Freire; (2) en economía, el examen de conciencia de base, emprendido por Albert O. Hirschman y Manfred Max Neef; (3) en antropología, la antropología social de apoyo de Adolfo Colombres e Isabel Hernández; (4) en historia, la corriente que toma en cuenta las versiones populares y los pueblos sin historia, como el enfoque de la microhistoria de Carlo Guinzburg; (5) en la etnología, el acercamiento a las culturas nativas con esquemas participativos, por ejemplo Rodolfo Stavenhagen y Guillermo Bonfil Batalla.

Fals Borda recibió los premios Bronislaw Malinowsky de la Sociedad para la Antropología Aplicada y Lectorazgo Martin Diskin, de la Asociación de Estudios Latinoamericanos, por su aporte a la ciencia social mediante la investigación-acción participativa ${ }^{44}$. Tras su fallecimiento, en 2008, se han publicado tres antologías de sus textos y numerosos artículos sobre su figura y sobre la investigación-acción participativa.

\section{Parecidos de familia entre la investigación-acción participativa y la teología de los signos de los tiempos en América Latina}

Se recurre a la categoría de parecidos de familia siguiendo una expresión que el mismo Fals Borda utiliza al mencionar el elenco de corrientes y referentes afines. Este autor afirma que "han aparecido análisis generales de nuestro campo que ayudan a delinear

\footnotetext{
${ }^{41}$ Ander-Egg, Repensando la investigación-acción-participativa, 35-39.

${ }^{42}$ Villasante, "Aportaciones básicas de la IAP a la epistemología y metodología”, 37.

${ }^{43}$ Rahman y Fals Borda, "La situación actual y las perspectivas de la investigación-acción participativa en el mundo", 185.

${ }^{44}$ Cruz, "Subversión, investigación-acción participativa y socialismo raizal: vigencia de la utopía en el pensamiento de Orlando Fals Borda".
} 
y configurar la 'familia participativa' que hemos venido construyendo" 45 , al hacer referencia a los métodos denominados autoinvestigación, ciencia social participante, encuesta participativa, encuesta concientizadora, encuesta feedback, autodiagnóstico, investigación militante, ciencia del pueblo y ciencia proletaria, método de sistemas flexibles, investigación acción, e investigación participativa ${ }^{46}$. También indica lo siguiente:

Se logró un conocimiento mutuo de lo que cada cual estaba haciendo en su medio y con herramientas investigativas propias, y se determinó no solo aquello que nos unía sino también las diferencias. Quedó reforzada la idea de que en verdad pertenecemos a la misma familia intelectual participativa, que hay una misma epistemología y metodología crítica inmanente. ${ }^{47}$

Si bien hay algunos antecedentes de recepción teológica de la investigaciónacción participativa ${ }^{48}$, lo que interesa aquí es considerar los aspectos convergentes entre el enfoque y una teología en América Latina que haya acogido los signos de los tiempos, tanto en sus fundamentos como en su práctica.

\section{Teología de los signos de los tiempos en América Latina}

La propuesta de Jesús de "saber interpretar [...] los signos de los tiempos" (Mt 16,3) y de "discernir el tiempo presente" (Lc 12,56), puesta en escena por Juan XXIII en la convocatoria del Concilio ${ }^{49}$, fue acogida por la Iglesia y quedó así consignada en la constitución pastoral Gaudium et spes ${ }^{50}$. Tanto el magisterio posterior como la teología posconciliar $^{51}$, especialmente la latinoamericana ${ }^{52}$, han buscado fundamentar dicho concepto y proponer una reflexión teológica sobre y desde "acontecimientos significativos que marcan la historia por su generalización y frecuencia, desencadenan conciencia

\footnotetext{
${ }^{45}$ Fals Borda, Una sociología sentipensante para América Latina, 321.

${ }^{46}$ Ander-Egg, Repensando la investigación-acción-participativa, 32 y 33.

${ }^{47}$ Fals Borda, Una sociología sentipensante para América Latina, 323.

${ }^{48}$ Por ejemplo, Cameron y otros, Talking about God in Practice. Theological Action Research and Practical Teology; Conde-Frazier, "Participatory Action Research", 234-243.
}

${ }^{49}$ Aunque Pío XII ya había utilizado en dos radiomensajes la expresión. Ver a Merino Beas, "La categoría teológica 'signo de los tiempos': usos e implicancias en el magisterio y la teología católica”, 66.

${ }^{50}$ Galli, "La interpretación teológica de los signos de los tiempos", 219; Schickendantz, "Una eclipse con dos focos: hacia un nuevo método teológico a partir de Gaudium et spes", 85-109.

${ }^{51}$ Silva Arévalo, "La significación teológica de los acontecimientos. El estatuto histórico de la teología según M.-D. Chenú", 269-297; Tracy, "Proyecto X. Retrospectiva y Perspectiva”, 514-527. Para una ponderación crítica de este enfoque, ver a Valadier, “Signos de los tiempos, signos de Dios?”, 328-333.

${ }^{52}$ Costadoat, "Los signos de los tiempos en la teología de la liberación", 399-412. 
y conmoción, esperanza y orientación en una época, creando un consenso básico o asentimiento universal" ${ }^{33}$.

El pueblo de Dios (especialmente los pastores y teólogos) está llamado a interpretar y discernir desde la fe y a la luz del Evangelio, en los signos, los planes y la presencia de Dios, los indicios de su providencia o, en expresión conciliar, los signos de Dios ${ }^{54}$. Tal discernimiento está orientado a una decisión pastoral, que el Espíritu convoca en orden a la misión, que tiene a Jesucristo como piedra angular:

Interpretar los sentidos de los hechos-signos desde el sentido final del plan de Dios cumplido en Cristo; y juzgar (diákrino) cada hecho, con un juicio teológico-moral, según su conformidad con el Evangelio y su ordenación a la meta escatológica. ${ }^{55}$

La II Conferencia del Episcopado Latinoamericano realizada en Medellín, en 1968, da cuenta de la recepción de los obispos en América Latina de la propuesta de discernir de los signos de los tiempos. Este aspecto se mantendrá vigente -aunque con algunos matices- hasta la V Conferencia en Aparecida:

El discernimiento de los signos de los tiempos en Medellín se orientó a penetrar el proceso de cambio con valores evangélicos, la transformación y la aspiración al desarrollo fueron "un signo y una exigencia", que llevaron a los obispos a proponer un camino de conversión y servicio que haga posible "vivir una verdadera pobreza bíblica que se exprese en manifestaciones auténticas". ${ }^{56}$

En la misma línea, la teología de la liberación interpretó que la irrupción de los pobres y la pobreza constituían -y constituyen- un signo prioritario para América Latina:

Para nosotros, el hecho histórico de la emergencia de los pobres como sujetos que luchan contra la opresión y en muchos casos lo hacen en virtud de un seguimiento explícito de Cristo, constituye un signo de los tiempos que, ulteriormente, da arraigo histórico y se convierte en criterio de interpretación al servicio de este tipo de teología. ${ }^{57}$

\footnotetext{
${ }^{53}$ Azcuy, "El Espíritu y los signos de estos tiempos. Legado, vigencia y porvenir de un discernimiento teológico", 602. A modo de ejemplo panorámico, ver a Silva Arévalo, "Auscultar los signos del tiempo presente y de la situación latinoamericana”, 582-614.

${ }^{54}$ Concilio Vaticano II, Constitución pastoral Gaudium et spes sobre la Iglesia en el mundo actual 4, 11 y 44.

${ }^{55}$ Galli, "La interpretación teológica de los signos de los tiempos”, 226.

${ }^{56}$ Azcuy, "La pobreza de la Iglesia y los signos de los tiempos. Medellín como recepción inacabada del Vaticano II", 110.

${ }^{57}$ Costadoat, “Seguimiento de Cristo en América Latina. Signo y criterio del acontecer de Dios”, 210-211.
} 


\section{Convergencias entre la investigación-acción participativa y la teología de los signos de los tiempos en América Latina}

Resulta relevante puntualizar el contexto histórico similar en el que se desarrollaron la investigación-acción participativa y la teología de los signos de los tiempos en América Latina. Como muy bien recuerda F. Berríos, el Concilio Vaticano II significó la apertura al mundo pero explicitó la apertura, en particular, al mundo moderno ${ }^{58}$. En diferentes documentos el Vaticano II se refirió al tema de los pobres y la pobreza ${ }^{59}$. Por ejemplo, en Gaudium et spes 63, los padres conciliares manifestaron su inquietud tanto por la desigualdad en las condiciones de vida y en el poder de iniciativa de los pobres como por el desprecio con que se los trata.

La recepción de Gaudium et spes por parte de la Iglesia latinoamericana significó considerar el compromiso que requería la misma realidad de los pobres y a la Modernidad "también en su aspecto de desarrollo desigual e injusto en las regiones del tercer mundo y especialmente en América Latina" ${ }^{60}$. La mayor novedad consistió en desplegar las consecuencias pastorales y teológicas y pensar como un signo de los tiempos el hecho histórico de la emergencia de los pobres como sujetos que luchan contra la opresión y el compromiso de toda la Iglesia -también de los teólogos- con ellos y su lucha ${ }^{61}$.

La teología de los signos de los tiempos reconoce que el sujeto para auscular, discernir e interpretar las voces del tiempo presente es todo el pueblo de Dios, entre los que destaca a pastores y teólogos ${ }^{62}$. Esto supone comprender todo el proceso como discernimiento comunitario, aspecto fundamental para escuchar la voz del Espíritu $^{63}$. La Iglesia ha manifestado el valor de la participación humana y cristiana y lo ha interpretado como uno de los signos de los tiempos ${ }^{64}$. La lectura de los signos de los tiempos, en gran parte de la tradición teológica latinoamericana, ha supuesto un teólogo creyente "junto con otros, en las comunidades y en la tradición de la Iglesia”"

\footnotetext{
${ }^{58}$ Berríos, "Antecedentes y recepción de Gaudium et spes en Latinoamérica. Una mirada desde Chile", 35.

${ }^{59}$ Azcuy, "La pobreza de la Iglesia y los signos de los tiempos", 102.

${ }^{60}$ Berríos, "Antecedentes y recepción de Gaudium et spes en Latinoamérica”, 35.

${ }^{61}$ Costadoat, "Seguimiento de Cristo en América Latina”, 210.

${ }^{62}$ Concilio Vaticano II, “Constitución pastoral Gaudium et spes 44.

${ }^{63}$ Azcuy, "Caminos de misión para estos tiempos. Hacia una Iglesia extrovertida, compartida, inclusiva y pneumática”, 57.

${ }^{64}$ Juan Pablo II, Exhortación apostólica postsinodal Chritifideles laici sobre la vocación y misión de los laicos en la Iglesia y el mundo actual 5.

${ }^{65}$ Costadoat, "Los signos de los tiempos en la teología de la liberación”, 134.
} 
El pueblo de Dios interroga, discierne, desde la propia historia, desde la tradición viva, el sentido de nuestro tiempo y de la voluntad divina. Una actitud de discernimiento que no tuviera en cuenta esta tradición, sería una total pérdida de identidad, un salto al vacío de la alienación. ${ }^{66}$

De esta manera se pone de relieve una temática clave: la articulación entre la sabiduría popular y la reflexión teológica. J. C. Scannone sostiene:

...el modelo para comprender la relación entre los saberes del pueblo y del intelectual [...] no debe ser unidireccional, sino que es el intercambio mutuo de saberes especificos, distintos, irreductibles entre sí, y válidos cada uno en su género. ${ }^{67}$

Implica asumir los aportes de los teólogos de a pie $e^{68}$ o, en palabras de M. Fiorito y M. Gil, según L. Gera, dar prioridad al conocimiento popular por sobre el aporte de otras disciplinas, aunque también estas sean útiles para la percepción y el discernimiento de los signos de los tiempos ${ }^{69}$.

La teología de los signos de los tiempos en América Latina se comprende como una teología interdisciplinaria. En América Latina, la teología ha desarrollado una recepción creativa del método de Gaudium et spes, al utilizar la mediación de las ciencias humanas y sociales "como mediación instrumental intrínseca al proceso mismo del método" 70 y guardar la práctica teológica su especificidad propia. En lo conceptual:

Las disciplinas que se ocupan de desentrańar estas variadas significaciones de la realidad son condición de posibilidad para que el teólogo comprenda mejor aquello que intenta discernir teológicamente, aunque no condición suficiente. La comprensión teológica de la realidad requiere de una multiplicidad de miradas. Las miradas que las disciplinas científicas ofrecen ayudan al teólogo a desentrañar el sentido creatural de la realidad, aunque ninguna de ellas por separado o conjuntamente puedan dar cuenta de la visión correspondiente a la teología. ${ }^{71}$

El diálogo con los hombres de buena voluntad y el diálogo entre los creyentes son constitutivos del proceso de discernimiento de los signos de los tiempos ${ }^{72}$.

\footnotetext{
${ }^{66}$ Fiorito y Gil, "Signos de los tiempos, signos de Dios. Apuntes para una teología, una espiritualidad y una pastoral de los signos de los tiempos", 71. Sobre algunos modelos comunitarios de discernimiento de los signos de los tiempos, ver a Bacher Martínez, "El discernimiento de los signos de los tiempos en el pueblo de Dios. Una lectura desde la teología pastoral fundamental”.

${ }^{67}$ Scannone, Evangelización, cultura y teología, 274.

${ }^{68}$ Silva y Costadoat, "Centro Teológico Manuel Larraín: una interpretación teológica del presente”, 507.

${ }^{69}$ Fiorito y Gil, "Signos de los tiempos, signos de Dios", 66 y 68.

${ }^{70}$ Scannone, "La recepción del método de Gaudium et spes en América Latina”, 41.

${ }^{71}$ Silva y Costadoat, "Centro Teológico Manuel Larraín”, 505.

${ }^{72}$ Fiorito y Gil, “Signos de los tiempos, signos de Dios”, 41.
} 
S. Silva subraya cómo la misma Gaudium et spes ${ }^{73}$ pone como condición de posibilidad del diálogo con el mundo al diálogo intraeclesial, lo que significa para la Iglesia una enorme exigencia de honestidad y coherencia ${ }^{74}$. Es necesario recordar que uno de los criterios para determinar que un conjunto de acontecimientos es un signo de los tiempos es el consenso o persuasión colectiva. La interacción y la comunicación -más o menos mediada- permiten avanzar en la configuración y constatación de los consensos.

El discernimiento de los signos de los tiempos está orientado a que la Iglesia cumpla con su misión de colaborar en la fraternidad universal y continúe con la obra de Cristo; a dar respuestas a la humanidad sobre el sentido de la vida presente, de la vida futura y la relación entre ambas; a percibir, entender y expresar mejor la verdad revelada. En definitiva, a descubrir en cada tiempo y lugar la presencia o los planes de Dios ${ }^{75}$. Para la Iglesia, la respuesta pasa por una decisión pastoral que renueve su misión a partir de una conversión pastoral ${ }^{76}$. Dice E. Silva:

Responder a esta situación es responder a Dios si se discierne su voz en medio de las voces de los hombres, si se reconoce su llamado en medio de esos llamados, si se descubre su acción/pasión en las acciones y pasiones de nuestros contemporáneos. Como el llamado de Dios se escucha en los llamados que nos interpelan a dar una respuesta, dar razón de esos llamados y de esas respuestas, como llamados de Dios y respuestas movidas por el Espíritu, es la tarea de la teología de los signos de los tiempos. ${ }^{77}$

Esta finalidad práctica requiere tener en cuenta cómo se articulan las diferentes funciones y carismas en el proceso de este discernimiento y toma de decisiones y un "ordenamiento estructural suficientemente representativo (órganos, organismos, asambleas, etc.), que implemente una sabia ordenación procesual de la decisión”78, que parta y se ordene a un compromiso práctico liberador como condición para percibir los signos y reflexionar sobre ellos ${ }^{79}$, y que sirva como instancia crítica de la misma comunidad en la que se inscribe.

En sintesis es posible percibir la convergencia entre la investigación-acción participativa y una teología de los signos de los tiempos en América Latina: (1) Se desarrollan en un mismo contexto histórico y convergen en hermenéuticas similares

\footnotetext{
${ }^{73}$ Concilio Vaticano II, Constitución pastoral Gaudium et spes 92.

${ }^{74}$ Silva, “¿Qué ha sido del diálogo en la Iglesia? De Pablo VI y Gaudium et Spes a hoy”, 381-405.

${ }^{75}$ Concilio Vaticano II, “Constitución pastoral Gaudium et spes 4, 11 y 44.

${ }^{76}$ Fiorito y Gil, "Signos de los tiempos, signos de Dios", 26.

${ }_{77}$ Silva, "Criterios de discernimiento para una teología de los signos de los tiempos latinoamericanos", 182.

${ }^{78}$ Fiorito y Gil, "Signos de los tiempos, signos de Dios", 41.

${ }^{79}$ Ibíd., 135.
} 
sobre América Latina; (2) comprenden que el sujeto de investigación es un colectivo, preferentemente popular; (3) el investigador está inserto y comprometido con los procesos comunitarios; (4) el diálogo constituye una mediación fundamental; (5) la intencionalidad práctica consiste en la liberación de los pueblos y de la misma ciencia.

A continuación se consideran los aportes que dicho método de las ciencias sociales le ofrece a una práctica teológica que busque percibir y discernir los signos de los tiempos.

\section{Esbozo metodológico de una teología de los signos de los tiempos en América Latina que recepcione la investigación-acción participativa ${ }^{80}$}

¿Cómo puede articularse una teología de los signos de los tiempos para poner de relieve las distintas voces del pueblo de Dios en tanto este está llamado a reflexionar desde la fe la historia presente, con el objeto de comprometerse con la misión al servicio del Reino? Es posible darle cauce de diferentes modos. Aquí se esbozarán algunas claves para ensayar la recepción de algunos elementos de la investigación-acción participativa. No es posible analizar todas las técnicas utilizadas ya que, como acuerdan los autores, "las técnicas propias de la investigación-acción participativa no descartan la utilización flexible y ágil de otras muchas derivadas de la tradición sociológica y antropológica, tales como entrevista, encuesta, observación, recurso a la documentación, etc." ${ }^{11}$ Por ello remito, en este punto, a trabajos antecedentes ${ }^{82}$, y esta reflexión se focaliza en algunos que pueden considerarse peculiares y decisivos para el enfoque.

Un primer aspecto a considerar es el origen de la solicitud del proceso de investigación-acción participativa, ya que es un factor condicionante de su ejercicio. Este puede ser el ámbito sociopastoral o el ámbito académico. En el primer caso, la propuesta subrayará la intencionalidad práctica y local del estudio, y la investigación teológica puede beneficiarse de manera mediata. Es posible que la práctica teológica quede inscrita institucionalmente bajo las actividades de extensión universitaria.

En el segundo caso, los requerimientos académicos configurarán espacios y tiempos de investigación. Por tal motivo se infiere que, para consolidar institu-

\footnotetext{
${ }^{80}$ Sigo en este punto los ejes propuestos por Ander-Egg en el Capítulo 4, "Fases e instrumentalización del proceso de la investigación-acción participativa" (Ander-Egg, Repensando la investigación-acciónparticipativa, 61-113).

${ }^{81}$ Ibíd., 78.

${ }^{82}$ Grieu, “'La Iglesia en la escuela de los creyentes más humildes? La importancia de los relatos de vida”, 355-383; Bacher Martínez, "Zarzas que arden. Aportes del estudio teológico-pastoral de casos a una teología de los signos de los tiempos", 389-415.
} 
cionalmente este segundo modelo, será necesario ejercitar la práctica teológica de manera independiente o desde una institucionalidad leve a fin de poder estimar objetivos alcanzables y plazos viables ya que, como indica P. López de Ceballos: "la investigación-acción participativa da frutos, pero a veces los impulsores soñaban con peras y las poblaciones deciden cultivar manzanas" ${ }^{83}$. Es decir, no es posible anticipar linealmente qué resultados o impacto son esperables de un procedimiento participativo.

Otra faceta a considerar, vinculada con la anterior, es quién propone la investigación-acción participativa teológico-pastoral con vista a los imaginarios sobre los roles comunitarios, las funciones asignadas en el proceso investigaciónacción participativa, la toma de decisiones pastorales a la que conduce el trabajo y a la utilización de información que surja en orden a su publicación. Es posible que se plasme en diversos escenarios: (1) Que el teólogo sea parte de la comunidad, en cuyo caso, si bien posee un conocimiento situado, necesita controlar el sesgo de su pertenencia durante la investigación, y cómo se reconfigura su rol a posterioridad del trabajo; (2) que el teólogo sea convocado por un miembro de la comunidad; en dicho caso, tanto si es propuesto por la autoridad como no, se requiere establecer cómo se articulan las funciones de animación del proceso y las implicancias de los distintos protagonistas en la toma de decisiones; (3) que el teólogo sea convocado por alguien externo a la comunidad, sea este de la academia o de la pastoral (autoridad), en cuyo caso, además de considerar los puntos anteriores, hay que ponderar la comunicación o no de la información resultante del itinerario.

En cualquier caso, estas variables se verán condicionadas por (1) el hecho de que el teólogo involucrado sea un bautizado ordenado o un bautizado que no haya recibido el orden sagrado; (2) si la investigación-acción participativa teológico-pastoral está animada por una sola persona o por un equipo; (3) si este equipo está constituido solo por teólogos o es interdisciplinario.

El proceso de implementación de una investigación-acción participativa, por medio de diversas técnicas, parte de la conceptualización inicial del enunciado de la investigación, ya que este no está supuesto a priori por los académicos. El discernimiento de los signos de los tiempos busca captar los signos de estos tiempos latinoamericanos. Esto puede hacerse en dos direcciones: reconociendo ejemplificaciones de signos ya enunciados para profundizar en su alcance y comprensión; o buscando los signos de los tiempos en su etapa germinal, esto es, los signos de los tiempos no en tanto constituidos sino en tanto emergentes. Esto supone rastrear la percepción colectiva sobre los acontecimientos y la ponderación que el pueblo de Dios a partir del sensus fidei va

${ }^{83}$ López de Ceballos, Un método para la investigación-acción participativa, 59. 
realizando y puede explicitar sobre ellos. La formulación del objeto del estudio y los sucesivos pasos de comprensión se dan así:

A partir de cuestiones puntuales y vivencias inmediatas que presenta la gente y que el equipo responsable va recogiendo, ordenando y sistematizando. En esta fase, uno de los aportes más importantes que puede hacer el agente externo [...] es el de sistematizar y devolver a la gente esas mismas experiencias, contextualizadas y relacionadas. Esta devolución sistemática de información es un modo de avanzar por aproximaciones sucesivas, hasta establecer un listado de cuestiones para estudiar y que las personas consideran significativas. ${ }^{84}$

Dos técnicas participativas que se destacan en la investigación-acción participativa son las asambleas y los grupos de discusión. Estos últimos se basan en la constitución de grupos asistidos por un coordinador que interviene en forma no directiva con el fin de obtener, intercambiar y cotejar información. El registro grabado o con notas es muy útil. Las asambleas están constituidas por un grupo numeroso de personas convocado para un propósito determinado en el proceso investigaciónacción participativa, y son útiles en los momentos en que el equipo animador realiza las devoluciones de los informes preliminares para su discusión y también con ocasión de la devolución final. El registro de las asambleas se realiza a través de actas.

Ambas técnicas son condiciones de posibilidad para generar un espacio y un tiempo situacional, esto es, producir una demarcación de sentido y, simultáneamente, constituir a la subjetividad capaz de habitar dicha situación mediante la desaceleración (pausas en un ambiente veloz y fluido). ${ }^{85}$ Como experiencia de comunión entre creyentes, la práctica anclará su fundamento último en la luz que suscita la acción del Espíritu como agente de koinonía, de intercomunicación y de diálogo" ${ }^{86}$ La asamblea es concebida en los siguientes términos:

Es un dispositivo de pensamiento. Pero este dispositivo no tiene expositor ni espectadores. Tampoco dispone de saberes ni opiniones. Más bien, estos están suspendidos, y solo serán convocados de ser necesitados [...]. En este sentido, el lazo en la asamblea es inevitablemente problemático y situacional. Que el lazo sea problemático y situacional significa que la asamblea se arma en un punto de no saber colectivo. Ahora bien, este no saber no describe la ignorancia de los allí reunidos respecto de un área específica. Este no saber describe un problema impensado y compartido por los allí reunidos. ${ }^{87}$

\footnotetext{
${ }^{84}$ Ander-Egg, Repensando la investigación-acción-participativa, 74.

${ }^{85}$ Lewkowicz, Cantarelli y Grupo Doce, Del fragmento a la situación. Notas sobre la subjetividad contemporánea, 106 ss.

${ }^{86}$ Rosolino, La teología como historia. Aportes recientes a la relación entre teología e historia, 364 ss.

${ }^{87}$ Ibíd., 117-118.
} 
Percibir cuáles son los signos actuales y los brotes que pueden indicar la emergencia de algún signo de los tiempos futuro es lo impensado y compartido por la comunidad que ha emprendido la investigación-acción participativa. Mediante las técnicas aludidas también se desarrolla el proceso de análisis e interpretación de la información. Es una etapa en la que el teólogo o equipo ofrece aportes teóricos a la discusión cuando estos son convocados: "A través de la interpretación se busca un significado más amplio de la información obtenida, mediante su trabazón e inserción con otros conocimientos disponibles (ya sea generalizaciones, leyes o teorías)" ${ }^{88}$, que permitirá avanzar hacia un discernimiento y a la toma de decisión, propuestas, proyecto y práctica pastoral. Es un espacio comunitario privilegiado para la lectura orante de la Biblia que, como un tercero, ilumina la reflexión de unos y otros.

En todas las etapas, el teólogo o equipo puede y debe desarrollar triangulaciones, esto es, cotejar diversos aspectos de la investigación para ponderar los datos obtenidos. Estas pueden ser metodológicas, de datos, de investigadores, teóricas o múltiples (combinación de dos o más de las anteriores). Este procedimiento, además de enriquecer el análisis e interpretación de la realidad que el grupo va realizando, permite trabajar con indicadores de validez en las investigaciones cualitativas que se volcarán a los informes académicos sobre el proyecto de investigación realizado con la metodología investigación-acción participativa.

Este método colabora a concretar una teología de los signos de los tiempos en América Latina, en la búsqueda de los signos de los tiempos en su etapa germinal por medio de grupos o comunidades cristianas en situación de reflexión y acción pastoral, sobre los aspectos de la actualidad que constituyen un desafío a su experiencia y compromiso cristianos. El servicio teológico académico realiza una opción por constituir el proceso de discernimiento desde ese no saber común. Cada integrante aporta sus vivencias y sus conocimientos y sabiduría creyente específica, en distintos momentos del proceso espiralado de descripción, análisis-interpretación, discernimiento, proyección y acción.

\section{Breve conclusión ponderativa}

¿Qué puede aportar la investigación-acción participativa a una teología de los signos de los tiempos en América Latina? Sin ánimo exhaustivo ni pormenorizado, puede inferirse que este enfoque ofrece a la teología, en primer lugar, una forma de profundizar la dimensión comunitaria y profética de todo el pueblo de Dios y concretar la misión

\footnotetext{
${ }^{88}$ Ander-Egg, Repensando la investigación-acción-participativa, 91.
} 
compartida requerida por la misión continental inspirada tanto en Aparecida como en la Iglesia en salida que propone la exhortación apostólica Evangelii gaudium ${ }^{89}$.

En segundo lugar ofrece una propuesta que subraya la dimensión pastoral y práctica del discernimiento de los signos de los tiempos, volviendo a reconciliar el sujeto eclesial que reflexiona con el que actúa, a semejanza del antecedente pastoral del método empleado por la Gaudium et spes, esto es, la revisión de vida utilizada en la Juventud Obrera Católica.

En tercer lugar brinda también un espacio de articulación entre la teología académica y la pastoral eclesial, posibilitando una instancia de diálogo fecundo entre los integrantes del pueblo de Dios, diálogo en el que están incluidos pastores y teólogos.

En cuarto lugar ofrece la posibilidad de profundizar la comprensión de los signos de los tiempos en sus nuevos lenguajes y prestar atención a emergentes epocales, lo que podría conducir a hipótesis de signos de los tiempos germinales.

Por último, ofrece un ámbito de diálogo y articulación entre áreas teológicas, y con otras disciplinas.

¿Cuáles podrían ser las dificultades para implementar una teología de los signos de los tiempos en América Latina con aportes de la investigación-acción participativa? Por una parte, hay una dificultad para encuadrar un proyecto de investigación que incluya investigación-acción participativa en los marcos de proyectos académicos, ya que no se puede formular al comienzo el objeto o hipótesis inicial de la investigación y no son previsibles los resultados, ni fácilmente determinables los tiempos.

Además, son proyectos que, según su alcance, requieren avales de la autoridad eclesial que habría que tramitar y que implican también clarificar la vinculación del discernimiento comunitario con la instancia de planificación pastoral entre todos los involucrados.

Por último, supone un perfil teológico dialogal y constructivo que, a su vez, se fundamenta en un estilo y una práctica: una capacidad de ensayar nuevos modelos de articulación entre personas, disciplinas, y diversas áreas teológicas.

Estimo que muchas prácticas teológicas, especialmente latinoamericanas, son afines tanto a la perspectiva como a los procedimientos de la investigación-acción participativa. Avanzar en un diálogo interdisciplinario teórico facilitará que se consolide el camino iniciado, una producción académica de mayor calidad, y la capacidad de diálogo entre diversos ámbitos disciplinares, la sabiduría del pueblo de Dios y la sabiduría de los pueblos en este tiempo y lugar.

${ }^{89}$ Azcuy, “Caminos de misión para estos tiempos”, 48. 


\section{Bibliografía}

Ander-Egg, Ezequiel. Repensando la investigación-acción participativa. Buenos Aires: Lumen, 2003.

Azcuy, Virginia. "Caminos de misión para estos tiempos. Hacia una Iglesia extrovertida, compartida, inclusiva y pneumática”. Anales de teología 5 (2012): 39-59.

. "El Espíritu y los signos de estos tiempos. Legado, vigencia y porvenir de un discernimiento teológico". Concilium 342 (2011): 601-612.

- "La pobreza de la Iglesia y los signos de los tiempos. Medellín como recepción inacabada del Vaticano II". En Teología de los signos de los tiempos latinoamericanos. Horizontes, criterios y métodos, editado por V. R. Azcuy, C. Schickendantz y E. Silva, 86-126. Santiago de Chile: Universidad Alberto Hurtado, 2013.

Azcuy, Virginia; Carlos Schickendantz; y Eduardo Silva (eds.). Teología de los signos de los tiempos latinoamericanos. Horizontes, criterios y métodos. Santiago de Chile: Ediciones Alberto Hurtado, 2013.

Bacher Martinez, Carolina. "El discernimiento de los signos de los tiempos en el pueblo de Dios. Una lectura desde la teología pastoral fundamental". Teología 122 (2017): 9-29.

- "Zarzas que arden. Aportes del estudio teológico-pastoral de casos a una teología de los signos de los tiempos". En Teología de los signos de los tiempos latinoamericanos. Horizontes, criterios y métodos, editado por V. R. Azcuy, C. Schickendantz y E. Silva, 389-415. Santiago de Chile: Universidad Alberto Hurtado, 2013.

Berríos, Fernando. "Antecedentes y recepción de Gaudium et spes en Latinoamérica. Una mirada desde Chile". En Teología de los signos de los tiempos latinoamericanos. Horizontes, criterios y métodos, editado por V. R. Azcuy, C. Schickendantz y E. Silva, 21-51. Santiago de Chile: Universidad Alberto Hurtado, 2013.

Berríos, Fernando; Jorge Costadoat; y Diego García (eds.). Signos de estos tiempos. Interpretación teológica de nuestra época. Santiago de Chile: Ediciones Universidad Alberto Hurtado, 2008.

Cameron, Helen y otros. Talking about God in practice. Theological Action Research and Practical Teology. London: SCM Press, 2010. 
Concilio Vaticano II. Constitución pastoral Gaudium et spes sobre la Iglesia en el mundo actual. Buenos Aires: Paulinas, 1983.

Conde-Frazier, Elizabeth. "Participatory Action Research". En The Willey-Blackwell Companion to Practical Teology, editado por B. J. Miller-Mc Lemore, 234-243. Chichester: Wiley, 2014.

Costadoat, Jorge. "Los signos de los tiempos en la teología de la liberación”. Teología y vida 47 (2007): 399-412.

- "Seguimiento de Cristo en América Latina. Signo y criterio del acontecer de Dios". En Teología de los signos de los tiempos latinoamericanos. Horizontes, criterios y métodos, editado por V. R. Azcuy, C. Schickendantz y E. Silva, 209-211. Santiago de Chile: Universidad Alberto Hurtado, 2013.

Cruz, Edwin. "Subversión, investigación-acción participativa y socialismo raizal: vigencia de la utopía en el pensamiento de Orlando Fals Borda". Izquierdas 14 (2012), http://www.izquierdas.cl/ediciones/2012/numero-14-diciembre (consultado 3 de marzo de 2016).

Demo, Pedro. Investigación participante: mito y realidad. Buenos Aires: LumenHumanitas, 2002.

Fals Borda, Orlando. "El tercer mundo y la reorientación de las ciencias contemporáneas". Nueva sociedad 107 (1990): 83-91.

. "La investigación participativa y la intervención social". Documentación social 92 (1993): 9-21.

- "Transformaciones del conocimiento social aplicado: lo que va de Cartagena a Ballarat". En Ciencia, compromiso y cambio social. Textos de Orlando Fals Borda. 254-284. Montevideo: El Colectivo-Lanzas y Letras, 2011.

- Una sociología sentipensante para América Latina. Antología y presentación Víctor Manuel Moncayo. Bogotá: Siglo del Hombre Editores-Clacso, 2009.

Fals Borda, Orlando y otros. Acción comunal en una vereda colombiana: su aplicación, sus resultados y su interpretación. Bogotá: Universidad Nacional de ColombiaDepartamento de Sociología, 1961.

Fiorito, Miguel y Daniel Gil. "Signos de los tiempos, signos de Dios. Apuntes para una teología, una espiritualidad y una pastoral de los signos de los tiempos". Stromata XXXII 1/2 (1976): 3-95. 
Galli, Carlos. "La interpretación teológica de los signos de los tiempos”. En El tiempo y la historia. Reflexiones interdisciplinares, editado por R. Ferrara y C. M. Galli, 219-232. Buenos Aires: Paulinas, 2001.

Grieu, Etienne. “¿La Iglesia en la escuela de los creyentes más humildes? La importancia de los relatos de vida". En Teología de los signos de los tiempos latinoamericanos. Horizontes, criterios y métodos, editado por V. R. Azcuy; C. Schickendantz y E. Silva, 355-383. Santiago de Chile: Universidad Alberto Hurtado, 2013.

Herrera Falfán, Nicolás y Lorena López Guzmán (comps.). Ciencia, compromiso y el cambio social. Orlando Fals Borda. Antología. Montevideo: Lanzas y Letras-El Colectivo-Extensión Libros, 2014.

Juan Pablo II. Exhortación apostólica postsinodal Chritifideles laici sobre la vocación y misión de los laicos en la Iglesia y el mundo actual. Buenos Aires: Paulinas, 1989.

Lewkowicz, Ignacio; Mariana Cantarelli y Grupo Doce. Del fragmento a la situación. Notas sobre la subjetividad contemporánea. Rosario (Argentina): Altamira, 2003.

Lonergan, Bernard. Método en teología. Salamanca: Sígueme, 2001.

López de Ceballos, Paloma. Un método para la investigación-acción participativa. Madrid: Popular, 1998.

Merino Beas, Patricio, "La categoría teológica 'signo de los tiempos': usos e implicancias en el magisterio y la teología católica". Anales de teología 8 (2006): 65-167.

Moncayo, Víctor Manuel. "Fals Borda: hombre hicotea y sentipensante". En Una sociología sentipensante para América Latina, por O. Fals Borda, presentación de la obra. Bogotá: Siglo del Hombre Editores-Clacso, 2009. Disponible en: Clacso, http://biblioteca.clacso.edu.ar/clacso/se/20160304050141/01pres.pdf (consultado 3 de marzo de 2016).

Negrete, Víctor. "A la memoria del maestro Orlando Fals Borda: bases y desarrollo de la investigación-acción participativa en Córdoba (Colombia)". International Journal of Psychological Recherche Vol. 1, No. 2 (2008): 85-87.

Rahman, N. Anisur y Orlando Fals Borda. "La situación actual y las perspectivas de la investigación-acción participativa en el mundo". Comunicación: Estudios venezolanos de comunicación (1996):14-20. 
Rosolino, Guillermo. La teología como historia. Aportes recientes a la relación entre teología e historia. Córdoba: Educc, 2004.

Salazar, María Cristina (ed.). La investigación-acción participativa. Inicio y desarrollo. Madrid: Popular, 2006.

Sánchez Lópera, Alejandro. "Orlando Fals Borda. Aporías de un pensamiento sin desilusión (11 de julio de 1925-12 de agosto de 2008)”. Nomadas 29 (2008): 207-211.

. "Orlando Fals Borda: la conmoción del rostro de las ciencia sociales". Revista colombiana de sociología Vol. 35, 2 (2012): 195-207.

Scannone, Juan Carlos. Evangelización, cultura y teología. Buenos Aires: Guadalupe, 1990.

. "La recepción del método de Gaudium et spes en América Latina". En La constitución Gaudium et spes. A los treinta años de su promulgación, por Sociedad Argentina de Teología, 19-49. Buenos Aires: San Pablo, 1995.

Schickendantz, Carlos. "Una eclipse con dos focos: hacia un nuevo método teológico a partir de Gaudium et spes". Teología 110 (2013): 85-109.

Silva Arévalo, Eduardo. "Auscultar los signos del tiempo presente y de la situación latinoamericana. Esbozo de algunos fenómenos a considerar para una interpretación teológica del presente". Teología y vida 46 (2005): 582-614.

- "Criterios de discernimiento para una teología de los signos de los tiempos latinoamericanos". En Teología de los signos de los tiempos latinoamericanos. Horizontes, criterios y métodos, editado por V. R. Azcuy, C. Schickendantz y E. Silva, 173-208. Santiago de Chile: Universidad Alberto Hurtado, 2013.

. "La significación teológica de los acontecimientos. El estatuto histórico de la teología según M.-D. Chenú”. Teología y vida 33 (1992): 269-297.

Silva Arévalo, Eduardo y Jorge Costadoat, "Centro Teológico Manuel Larraín: una interpretación teológica del presente”. Teologia y vida Vol. XLVI (2005): 503-509.

Silva, Sergio. “¿Qué ha sido del diálogo en la Iglesia? De Pablo VI y Gaudium et spes a hoy". Anales de teología 5 (2012): 381-405.

Toulmin, Stephen y Bjørn Gustavsen (eds.). Beyond Theory: Changing Organizations Through Participation. Amsterdam: John Benjamins Publisching Co., 1996. 
Tracy, David. "Proyecto X. Retrospectiva y perspectiva”. Concilium 190 (1983): 514-527.

Valadier, Paul. “¿Signos de los tiempos, signos de Dios?” Criterio 45 (1972): 328-333.

Villasante, Tomás. "Aportaciones básicas de la IAP a la epistemología y metodología”. Documentación social 92 (1993): 23-41.

Wittgenstein, Ludwig. Investigaciones filosóficas. Barcelona: Altaya, 1999. 